\section{A National University Library.}

IT must be the experience of any graduate of Oxford or Cambridge who is residing at a distance from those university towns that a serious obstacle to the prosecution of research arises from the impossibility of consulting the university libraries, and the absence of any provision for borrowing volumes, or obtaining references under arrangements similar to those pertaining at the libraries of the Roral and other scientific societies. Moreover, while Oxford and Cambridge possess the special privilege of acquiring free copies of books copyrighted in England, there are now many universities in this country which are far too poor to keep up even a decently respectable library in any branch of science.

The conditions of modern times have created a need for it National University Library, enjoving the same privileges as the Oxford and Cambridge libraries, and which should be available for graduates of any british university; persons engaged in any specified branch of research to have the opportunity of borrowing books through the post as in the case of the Royal Society.

G. H. BRYAN.

\section{Mutation.}

THE term mutation is applied in biology to that sort of variation in which the equilibrium of the organism seems to be disturbed, and a new position of equilibrium is found, which is markedly different from the original one. This may apply to a whole organism or merely to some one organ, so far as external appearances show.

In all the discussions regarding mutation which have lately taken place, the difficulty has been felt that it is impossible by any methods yet known to perceive and measure the internal changes and influences leading to mutability. It is certainly not supposed that mutability is without cause, but it is obviously difficult to detect the causes which bring it about.

It occurs to me that some help may be obtained from analogies derived from psychology and sociology. What mutation is in biology, conversion is in psychology, and revolution in sociology. It may be said that to assume such parallels is merely to beg the question, but I think that the apparent parallelism cannot be without significance. Now the phenomena leading towards conversion have been studied subjectively (cf. James, "Varieties of Religious Experience"), and those leading towards revolution have been studied objectively, with certain well-defined results. If the supposed analogy is a valid one, it appears to follow that mutability is due to the same general causes as ordinary variability (just as change of opinion and reform are due to the same general causes as conversion and revolution), but that there is this differencemutability represents an explosion of energy, as it were, in a given direction, and therefore differs from ordinary variation somewhat as the firing of a gun differs from the explosion of a loose heap of powder. It also follows that the cause of the explosion is not plasticity in the organism, but in some measure the reverse; that is, the power of being influenced, and at the same time of withstanding the expression of the influence until it had acquired considerable force. This implies a certain rigidity of type, quite comparable with a type of mind familiar to all. It further appears to follow that the chance of mutations succeeding from the first is comparatively remote, though such a thing is quite possible; but since they are the result of general causes, the sort of changes the mutations exhibit are likely to come about in due course, just as the sort of changes represented by a revolution are likely to prevail ultimately, though the revolution itself may appear to fail.

$$
\text { T. D. A. Cockerell. }
$$

Lniversity of Colorado, Boulder, Colorado, January 2.5.

\section{Fact in Sociology.}

Mr. Wells is a dangerous man to criticise. "Such thunderbolts as " crude," " dull," " balderdash," come hurtling at one's head even from his modified letters

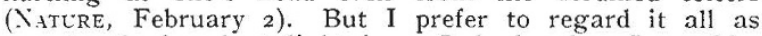
meant only for sheet lightning. Indeed, when I consider the courtesy that characterised my article (NATURE, December 29), plain-spoken though it was on some points, I cannot take any other view.
Now to Mr. Wells's points in order.

(x) " "The Food of the Gods' does not claim to forecast the future." My mistake was natural. It only shows the risk Mr. Wells runs in appearing before the world in two entirely different characters. Still, I hit upon a weak point. He pictures an ideal State, but cannot show us how it is to be realised. Archimedes had no fulcrum for the lever with which he would have moved the world. Mr. Wells has no power to apply to his.

(2) "I have mixed up' Anticipations' and 'Mankind in the Making.'" Why keep them separate? "Anticipations " also deals largely with ideals.

(3) $R e$ the question-Which of the great national " syntheses" will attain predominance, see "Anticipations," chap. viii. passim, and especially pp. тоo, ror (6d. ed. 1904). This chapter seemed to me an interesting speculation, but Mr. Wells describes what $\mathrm{I}$ thought, and, on re-reading, think is to be found in it as "balderdash." True, through inadvertence I wrote "Anglo-Saxon" instead of "English-speaking," for which I am sorry.

(4) Re the recruiting of the upper strata of society from the lower, nothing, he says, is known about this. Still, those who have studied human evolution think they know something. Prof. Karl Pearson even says that there are " class statistics" for the population of Copenhagen, and writes, " the population would accordingly appear to be ultimately, and in the long run, reproducing itself from the artisan classes" (Natural Science, May, 1896). Dr. Mercier (see the Sociological Society's papers, I904, p. 55) regards " a civilised community in the light of a lamp, which burns away at the top and is replenished at the bottom." As to " stagnant" classes, I find in "Anticipations," p. I21, "It (the new Republic) will tolerate no dark corners where the people of the Abyss may fester, no vast diffused slums of peasant proprietors, no stagnant plague preserves." See especially p. i I7 for Mr. Wells's plan for getting rid of undesirable types. As to careful parentage, see "Mankind in the Making," p. 99:-“'The first step to ensuring them (the ends aimed at) is certainly to do all we can to discourage reckless parentage.'

In conclusion, let me describe myself as a much-battered but not unfriendly critic of the New Republic. F. W. H.

\section{The Melting of Floating Ice.}

May I suggest that Dr. Deventer, of Amsterdam, whose letter to you is referred to in your issue of January 26 (p. 303), has discovered a "mare's nest"?

His observant pupil, who noticed that in a glass filled to the brim with water and floating ice the melting of the latter did not cause overflow, was apparently totally ignorant of the laws of flotation, or he would not have expected otherwise. Why should the level of the water change? The ice in melting must of necessity just fill with water the space that it displaced when floating, and so the level remains unaltered. So Dr. Deventer's statement that "when a vessel contains a solid floating in its own liquid, the level of the latter does not change by the melting of the solid "appears quite superfluous.

As to making this a "general " law applying to solids floating in their own liquids, surely the rule is that solids do not do so, but sink. Why make a general law which only applies in the case of a very few exceptional substances, such as ice, cast iron, and bismuth? HFAT.

February 8 th

\section{A Lunar Rainbow.}

LAST night, after ro p.m., a thunderstorm passed over this town, travelling from west to east. When the stcrm had passed and the rain had almost ceased, a bright quartermoon shone brilliantly almost overhead. To the east the clouds were still very heavy and dark, and in that direction there appeared a perfect rainbow. The arc of the bow was low; it appeared as a grey band with a certain suggestion of colour, against the dark leaden sky.

I should be glad to know from any of your readers if such moon rainbows are of common occurrence, as the one of last night is the first which I have seen.

Pretoria, Transvaal, January I $_{5}$.

\section{J. McCrar.}

